\title{
A GESTÃO DEMOCRÁTICA NO CONTEXTO DO MUNICÍPIO DE QUEIMADOS (RJ): A TRAJETÓRIA DE ELEIÇÃO PARA DIRETORES ESCOLARES
}

\author{
GESTIÓN DEMOCRÁTICA EN EL CONTEXTO DEL MUNICIPIO DE QUEIMADOS \\ (RJ): EL CAMINO DE ELECCIÓN PARA LOS DIRECTORES ESCOLARES
}
DEMOCRATIC MANAGEMENT IN THE CONTEXT OF THE MUNICIPALITY OF QUEIMADOS (RJ): THE ELECTION PATH FOR SCHOOL PRINCIPALS

\author{
Bethânia BITTENCOURT ${ }^{1}$ \\ Daniela Patti do AMARAL ${ }^{2}$
}

RESUMO: O presente artigo debate a trajetória da eleição de diretores das escolas públicas, desde a emancipação na década de 1990, no município de Queimados, localizado no estado do Rio de Janeiro, na região sudeste do Brasil. Por meio de análise documental de textos dos poderes executivo e legislativo, pode-se observar que a participação, como dimensão de gestão democrática (LIMA, 2014) afasta-se do centro deste processo. Aspectos relacionados ao desempenho do candidato à direção escolar são cruciais para a participação no pleito e estão sob o crivo do poder executivo. Ademais, a eleição de diretores expressa nos documentos legais gera uma espécie de auto fidelidade, visto a meta 19 do Plano Nacional de Educação que regulamenta a seleção de diretores por meio de consulta pública.

PALAVRAS-CHAVE: Gestão democrática. Eleição de diretores. Seleção de diretores escolares. Gestão escolar.

RESUMEN: Este artículo debate la trayectoria de la elección de directores de escuelas públicas desde la emancipación, en la década de 1990, del municipio de Queimados, ubicado en el estado de Rio de Janeiro, en la región sureste de Brasil. A través del análisis documental de textos de los poderes ejecutivo y legislativo, se puede observar que la participación, como dimensión de la gestión democrática (Lima, 2014), se aleja del centro de este proceso. Aspectos relacionados al desempeño del candidato a la dirección escolar son fundamentales para la participación en el pleito y están bajo el control del poder ejecutivo. A elección de directores basada en los documentos legales genera una especie de autofidelidad, una vez que la meta 19 del Plan Nacional de Educación, que condiciona la selección de directores por medio de la consulta pública.

PALABRAS CLAVE: Gestión democrática. Elección de directores. Selección de directores de escuela. Gestión escolar.

1 Universidade Federal do Rio de Janeiro (UFRJ), Rio de Janeiro - RJ - Brasil. Doutoranda no Programa de Pós-graduação em Educação. ORCID: https://orcid.org/0000-0002-7879-8900. E-mail: bethania1707@gmail.com

2 Universidade Federal do Rio de Janeiro (UFRJ), Rio de Janeiro - RJ - Brasil. Professora Associada na Faculdade de Educação e Docente no Programa de Pós-graduação em Educação. ORCID: https://orcid.org/00000002-9234-1843. E-mail: danielapatti.ufrj@gmail.com

RPGE- Revista on line de Política e Gestão Educacional, Araraquara, v. 25, n. 1, p. 168-187, jan./abr. $2021 . \quad$ e-ISSN:1519-9029 
ABSTRACT: This article discusses the election of public-school principals since the emancipation, in the 1990s, of the municipality of Queimados, located in the state of Rio de Janeiro. Through documentary analysis of texts from the executive and legislative branches, it can be observed that participation, as a dimension of democratic management, is in the center of this process. Aspects of the performance of the candidate are important for the election and the election of directors according to legal documents generates a kind of selfloyalty, in view of goal 19 of the Brazilian National Education Plan, which regulates the selection of directors through public consultation.

KEYWORDS: Democratic management. Election of school principals. Selection of school directors. School management.

\section{Introdução}

Presente nas normativas legais brasileiras há cerca de trinta anos, a gestão democrática da escola pública brasileira é um princípio, efeito das disputas e embates ocorridos no período de reabertura democrática do Brasil, após mais de vinte anos de ditadura civil-militar. Como afirmado por Rocha e Hammes (2018) a gestão democrática é um grande desafio para a construção de uma escola em que todos os seus segmentos sejam contemplados, em especial os alunos que, em última análise, são o sentido de toda escola. Conforme os autores, a democracia passou a ser, em tese, o escopo de toda a gestão dos órgãos públicos do país a partir da abertura democrática do Brasil na década de 1980, tendo como marco a constituinte que culminou com a Carta Magna Nacional de 1988 (BRASIL, 1988).

O presente trabalho discute os pressupostos sobre a gestão democrática da escola pública, do debate teórico e conceitual, a partir das contribuições de Lima (2014), sobre as dimensões da gestão democrática da educação: eleição, colegialidade e participação. Dessas dimensões, destacamos a eleição de diretores para debruçarmos nossa discussão e análise a partir do movimento realizado desde a década de 1990 no município de Queimados, um dos municípios que compõem a Baixada Fluminense, região geopolítica composta por treze cidades no estado do Rio de Janeiro.

A escolha do universo da pesquisa se associa à dissertação de mestrado da qual o artigo se originou, considerando um município no estado do Rio de Janeiro que legislou a seleção de diretores escolares, através da eleição direta, logo após a sua emancipação, em 1990. A eleição está presente na Lei Orgânica Municipal (QUEIMADOS, 1993) confirmando o princípio de gestão democrática posto na Constituição Federal (BRASIL, 1988). A lei no 187 (QUEIMADOS, 1995), antes mesmo da gestão democrática ser ratificada na Lei de Diretrizes e Bases da Educação no 9394/96 (BRASIL, 1996), regulamentou como esse 
processo se daria. Embora retrate um contexto local, colabora na compreensão das possibilidades e limitações da eleição de diretores enquanto formato de seleção para esta função nas escolas públicas.

O presente trabalho, de caráter qualitativo, utilizou a análise documental para investigar como os textos políticos do município de Queimados (RJ) tratam a eleição de diretores e seus desdobramentos, contemplando o perfil do candidato e a forma de participação da comunidade: quem pode se candidatar, quem vota, qual formação exigida para ser diretor de escola, quais os requisitos que deve preencher para concorrer ao pleito.

O trabalho está dividido em quatro seções após esta introdução: o debate teórico acerca das dimensões da gestão democrática propostas por Lima (2014); a discussão sobre a dimensão da eleição de diretores, suas possibilidades e limites; a trajetória da eleição no município de Queimados (RJ), o movimento de infidelidade normativa e auto fidelidade ao descolar-se do Plano Nacional de Educação (BRASIL, 2014), mas reafirmar sua opção pela eleição de diretores no Plano Municipal de Educação (PME) (QUEIMADOS, 2015) e, por fim, as considerações finais.

\section{Dimensões da gestão democrática: eleição, colegialidade e participação}

A gestão democrática das escolas é uma complexa categoria político-educativa que não dispensa a análise dos contextos históricos, dos projetos políticos, da correlação de forças em que ocorre, por ser uma construção social (LIMA, 2014). Tal assertiva corrobora para a nossa compreensão de negação de relações rasas com a gestão democrática, que não consideram a participação dos atores escolares e dos espaços colegiados da escola.

Podemos compreender a gestão democrática como o conjunto de relações de participação na escola entre os diferentes coletivos que a compõe: alunos, pais, responsáveis e famílias, docentes, funcionários não docentes, sujeitos possíveis como público da escola, entre outros, sendo que a soma desses coletivos, no Brasil, é comumente chamada de comunidade escolar. Esse conjunto de relações envolve a horizontalização destes coletivos na identificação de problemas, demandas e questões locais específicas, o debate de possíveis soluções e o empenho dos coletivos em resolvê-los, equalizá-los e transpô-los.

Lima (2014) defende três dimensões básicas associadas à gestão democrática: a eleição, a colegialidade e a participação na decisão. No entanto, as dimensões apresentadas pelo autor não são receita ou prescrição de gestão democrática garantida e plena; não esgotam as perspectivas de gestão democrática na escola. Podemos encontrar na cena das escolas 
públicas outras formas de participação, para além das regulamentadas, como assembleias, associações e fóruns que contam com a participação dos diferentes atores. Em outras palavras, o fato de se observar as três dimensões no âmbito escolar - eleição dos diretores, espaços de colegialidade (conselho escolar, grêmios, associação de pais, conselho de classe, conselhos de alimentação escolar e do $\mathrm{FUNDEB}^{3}$, entre outros) e participação - não afasta possíveis limitações do exercício da gestão democrática nas escolas públicas.

A eleição, foco deste trabalho, remete a escolha do diretor de escola de forma direta pelos sujeitos escolares. Entretanto, a eleição não somente permite a participação daqueles que escolhem o diretor, mas igualmente daqueles que optam por disputar o pleito. Podemos afirmar, assim, que a eleição aprimora a democratização da escola por dois vieses, como uma via de mão dupla.

A colegialidade possibilita que muitas das demandas da escola, inscrita em práticas democráticas e horizontalizadas, sejam discutidas nos espaços colegiados compostos por representantes dos diferentes coletivos escolares no conselho escolar, conforme previsto Lei de Diretrizes e Bases da Educação (LDB), Lei no 9394 (BRASIL, 1996) e em colegiados de nível municipal, estadual e nacional, como conselhos de educação, de acompanhamento do FUNDEB e de alimentação escolar.

A participação é uma dimensão crucial que permeia todas as outras, uma vez que não é compreensível a eleição e a colegialidade sem que os sujeitos participem, atuem e decidam. Uma forma de participação dos coletivos é na construção, revisão e reelaboração do Projeto Político Pedagógico - PPP, documento que estrutura as mudanças e transformações que a escola pretende alcançar em seu contexto, num determinado período, forma normativamente definida na LDB (BRASIL, 1996).

Uma questão apontada por Lima $(2014 ; 2018)$ é a cristalização da gestão democrática quando esta se transforma em um slogan ou um lugar-comum repetitivamente conclamado, no sentido de ser evocada sem que seja de fato praticada ou que aconteça pontualmente em escassas ocasiões. Nesse sentido, a gestão democrática é um aspecto de difícil aferição e não se limita a momentos de participação pontual na escola, tampouco o atendimento esporádico de exigências que visam o mero procedimentalismo, como a existência de conselhos escolares e do projeto pedagógico, como necessários ao atendimento legal da LDB (BRASIL, 1996). Os

3 O FUNDEB é o Fundo de Manutenção e Desenvolvimento da Educação Básica e de Valorização dos Profissionais da Educação atende toda a educação básica, da creche ao ensino médio. O Fundeb tem como principal objetivo promover a redistribuição dos recursos vinculados à educação. $\mathrm{O}$ acompanhamento e o controle social sobre a distribuição, a transferência e a aplicação dos recursos do programa são feitas em escalas federal, estadual e municipal por conselhos criados especificamente para esse fim. Disponível em: http://portal.mec.gov.br/fundeb. Acesso em: set. 2019.

RPGE- Revista on line de Política e Gestão Educacional, Araraquara, v. 25, n. 1, p. 168-187, jan./abr. $2021 . \quad$ e-ISSN:1519-9029 
problemas referentes a concretização democrática do PPP podem ser apontados quando são feitos por um único ator escolar, sem a participação dos docentes, funcionários e estudantes da escola em sua elaboração ou que não são completados sob a prerrogativa de que estão em construção, mas que nunca ficam prontos (FERNÁNDEZ, 2015). Quanto aos conselhos escolares, podemos citar problemas como a formação assumida por indivíduos pré-definidos pela direção escolar ou a convocação de seus integrantes para legitimar uma decisão que já fora definida, esvaziando o seu caráter deliberativo.

O tema da gestão democrática pode aparecer em projetos político-pedagógicos, planos de gestão ou ação, planos municipais/estaduais de educação sem, no entanto, permear as ações cotidianas escolares. Para Santos e Sales (2012), essa questão atravessa a utilização da gestão democrática como mote à convocação e sensibilização dos sujeitos para a realização de tarefas que se distanciam da descentralização do poder e da participação dos coletivos da escola na tomada de decisões. A democracia e as práticas de colegialidade democrática, assim como a autonomia na participação nas decisões e capacidade de produção de regras próprias, em direção às formas de "endogoverno democrático" (LIMA, 2018, p. 24), estão longe de constituir simples técnicas de gestão ou mesmo de princípios políticos constitucionalmente legitimados em certos casos. Conforme destacado pelo autor, são práticas educativas e de aprendizagem da democracia através do exercício da participação nos processos de tomada da decisão e um direito de professores, alunos, famílias e comunidade.

Diante das possibilidades que a gestão democrática nos amplia e, proporcionalmente, das dificuldades de concretizá-la, dado que a confirmação da existência do PPP e do conselho de classe não implica numa gestão democrática de fato, como podemos pensar neste princípio em forma de meta, tal qual é expressa no Plano Nacional de Educação (PNE) (BRASIL, 2014)? Poderia a gestão democrática ser traduzida como meta? Quais seriam as ações mais concretas e como poderíamos partir para garantir uma gestão democrática, sabendo que esta demanda vigília permanente?

Uma pista possível é saber que a existência de conselhos escolares e de um projeto pedagógico na escola não é suficiente, para além, é necessário compreender e identificar como os representantes destes espaços colegiados são escolhidos, com que frequência se reúnem, como são definidas as pautas. Do mesmo modo, para além de identificar a existência de um projeto pedagógico, questiona-se como e quem participa da sua elaboração e revisão, bem como a periodicidade deste processo. Outra pista, foco do presente artigo, é o processo de seleção dos diretores escolares. 


\section{A eleição de diretores como dimensão da gestão democrática}

A eleição para a escolha de diretores de escolas públicas é defendida por vários autores que a consideram como a via mais democrática de seleção (SOUZA, 2009; LIMA, 2014; MENDONÇA, 2001; PARO, 2007; 2011; 2016; AMARAL, 2018). Quando comparada a outras formas mais comuns - indicação política e concurso -, a eleição se destaca como uma opção que se afasta dos interesses políticos partidários da indicação por meio do poder executivo ou legislativo e da impessoalidade característica do concurso público.

Nessa lógica, a eleição se constitui como um espaço de participação tanto daqueles que atuam na escola, os que são por ela atendidos, quanto por aqueles que podem candidatarse à função - desde que atendam aos critérios para se candidatar, o que é definido por cada rede de ensino no Brasil, dada a relativa autonomia das instâncias subnacionais conforme determina a Constituição Federal (CF) (BRASIL, 1988). A eleição, em geral, movimenta toda a comunidade escolar antes mesmo da sua execução através das comissões de acompanhamento, das campanhas das chapas e da apuração desse processo, e, conforme Paro (2007), a democratização da escola não se reduz à eleição de diretores, uma vez que não é um processo cotidiano.

A eleição pode acontecer bianualmente ou com intervalo maior e esse é um fator definido por cada instância subnacional em sua rede de educação, como expressão da sua responsabilidade e autonomia. Outro aspecto que cada contexto delimita é o número de reconduções de um mesmo diretor a função. Não limitar a quantidade de reconduções ou ampliar esse número por uma grande quantidade de mandatos esvazia a possibilidade de proporcionar a outros sujeitos o acesso à direção de escola e, consequentemente, a outros projetos, cede à personalização da função, reprime a oxigenação da gestão. Não é difícil vermos casos de diretores escolares que, mesmo eleitos, permanecem nesta posição por muitos anos e até mesmo décadas.

No Brasil, as formas mais comuns de condução da função de diretor são, além da eleição, a indicação política e o concurso, este último em menor escala. A indicação é o modelo considerado menos democrático por levar em conta a possibilidade de o diretor ser um representante dos interesses do poder executivo ou legislativo naquele contexto atendido pela escola. Não obstante, o diretor indicado pode também ser um preposto das forças dominantes naquele lugar. Sobre esse modelo, temos que:

A nomeação por critério político, em que o secretário de educação ou o chefe do poder executivo escolhe o ocupante do cargo, tendo como base o 
critério político-partidário, é comumente considerada a pior alternativa, em virtude do clientelismo político que ela alimenta e a falta de base técnica que a sustente, já que o candidato é escolhido não por sua experiência e conhecimento de gestão e de educação, mas por sua maior afinidade com o partido ou o grupo no governo do estado ou do município (PARO, 2011, p. $45)$.

Sobre a indicação política do diretor de escola em atendimento aos interesses clientelistas, Mendonça (2001) sustenta que a interferência política tem na escola um campo fértil para crescer:

Para o político profissional, ter o diretor escolar como aliado político é ter a possibilidade de deter indiretamente o controle de uma instituição pública que atende diretamente parte significativa da população. Para o diretor, gozar da confiança da liderança política é ter a possibilidade de usufruir do cargo público. Estabelecem-se, desta maneira, as condições de troca de favores que caracterizam o patrimonialismo na ocupação do emprego público. Essa forma de provimento, que denominei indicação, baseia-se na confiança pessoal e política dos padrinhos e não na capacidade própria dos indicados, ficando distante da ordenação impessoal que caracteriza a administração burocrática. A exoneração segue, nesse sentido, a mesma lógica. Na medida em que o beneficiado com o cargo perde a confiança política do padrinho, a exoneração é acionada como consequência natural, como o despojamento de um privilégio (MENDONÇA, 2001, p. 89).

Dessa forma, a escola é percebida como um espaço de troca de favores entre políticos e possíveis eleitores, o que caracteriza o clientelismo. As funções social e pedagógica da escola ficam em detrimento a esses interesses. A exoneração dos diretores indicados rodeia a escola, o que pode acarretar a rotatividade de diretores, em uma mesma escola regulada ao interesse de seu padrinho político personificado como representante do poder executivo, legislativo ou mesmo outro sujeito que detenha algum tipo de poder e controle no território em que a escola se encontra e que é o indicante do diretor à função. Para Mendonça (2001), a indicação está numa relação de interesses e confiança pessoal e política desses padrinhos e não na capacidade própria ou técnica dos indicados. A opção pela indicação política do diretor escolar aponta para mais problemas do que possibilidades para a escola, já que esta é vista nesse modelo de provimento como um lugar de atendimento de interesses pessoais, políticos e individuais.

No caso do concurso, não se trata de a atuação do diretor ser uma função, mas sim um cargo, isso devido ao fato de o diretor permanecer exercendo essa atividade até que se aposente ou se abdique do cargo. Embora seja uma forma mais impessoal de conduzir o profissional à função diretiva escolar, o concurso demonstra problemas exatamente pelo excesso de impessoalidade. Não se defende aqui que o concurso público não seja uma opção 
adequada a outros casos, mas, especificamente em relação à função de diretor escola, é necessário que se pontue as fragilidades por esta opção. Paro (2011) afirma que não se pode negar a importância do concurso público para a atribuição de cargos de modo a afastar as práticas de nomeações políticas que tendem a favorecer interesses pessoais e privados em oposição ao interesse público, mas é preciso perceber as suas limitações especialmente quando no debate de gestão democrática.

Ao aferir o desempenho do candidato à direção escolar, seja através de instrumentos geralmente utilizados nos concursos públicos, concursos internos e processos seletivos, como as provas escritas, redações, análise de currículo e/ou planos/projetos de gestão/ ação etc., não se observa a relação do candidato com a comunidade escolar e a percepção dessa comunidade para o candidato tampouco a sua participação na seleção. Nesse caso, ainda, diferente do diretor indicado que deve justificativas ao seu padrinho político, o diretor concursado pode ser visto exclusivamente como um executor das políticas do Estado de forma verticalizada, com pouco ou nenhum diálogo com a comunidade, o que, nas duas opções, esvaziam as possibilidades de atendimento às reivindicações oriundas da escola, ou seja, privilegia-se a competência técnica em detrimento da liderança política (PARO, 2011; MENDONÇA, 2001).

A eleição, concebida neste artigo como forma mais democrática, não é livre de limitações e formas de reduzir o seu potencial de participação. Podemos listar algumas destas limitações como eleições que definem eleitores somente um grupo restrito de atores escolares a partir de um corte de idade, possibilidade de ilimitadas reconduções à função, a exigência de perfil de candidato muito específico que contempla um número reduzido de possíveis candidatos etc. Igualmente, problemas como excesso de personalismo na figura do candidato, falta de preparo de alguns deles, populismo e atitudes clientelistas, comportamento de apropriação da função pelo candidato eleito, são apontados como fragilidades desse processo (MENDONÇA, 2001). Isso nos leva a refletir e a problematizar que a existência da eleição em um sistema de ensino não aponta para a garantia de uma democratização da gestão da escola e das relações ali compreendidas, até mesmo porque, como já defendido aqui, a eleição por si somente, não garante a gestão democrática, uma vez que esta é um processo contínuo, não resultante de ocasiões pontuais.

Ainda de acordo com Mendonça (2001), a eleição de diretores foi adotada por vários sistemas de ensino como iniciativa de democratização da gestão, mesmo antes da promulgação da CF, em 1988. Tal tendência ocorreu no município de Queimados quando o poder legislativo disciplinou a eleição de diretores das escolas públicas da rede municipal por meio da lei n 187/ 95 (QUEIMADOS, 1995), antes mesmo da LDB. Entende-se que, a partir 
da asserção de Ball (1994), os textos políticos são resultados de processos políticos em contextos interrelacionados. Trata-se da relação do contexto nacional de reabertura democrática, dos movimentos que antecederem e se desencadearam a partir desse marco e a interpretativa do contexto local na tentativa de democratizar a gestão da escola pública. Bowe, Ball e Gold (1992) apontam a esse respeito a relação simbiótica do contexto da influência com o contexto da produção dos textos das políticas. A influência do movimento de redemocratização do país pode, em maior ou menor medida, assinalar a intenção local de promover a participação dos atores escolares na escolha da direção de escola.

\section{A trajetória da eleição de diretores no município de Queimados (RJ)}

No contexto brasileiro, os municípios passaram a ter relativa autonomia para legislarem e formularem políticas, após a promulgação da CF (BRASIL, 1988), e atuam em regime de colaboração, diferentemente de outros países. Assim, o município de Queimados, ao emancipar-se no início da década de 1990, iniciou o seu processo de elaboração de textos políticos para seu sistema educacional. A lei no 187 (QUEIMADOS, 1995), sancionada cinco anos após emancipação da cidade, representou atenção, naquele momento, quanto à democratização da gestão da escola e ratificou o que fora definido na Lei Orgânica Municipal (QUEIMADOS, 1993). Ao ser aprovada, franqueou a candidatura à função diretiva aos professores e aos especialistas da educação, mas em contrapartida, limitou o grupo de eleitores aos alunos maiores de 16 anos, responsáveis dos alunos com idade inferior a 16 anos e aos servidores públicos em efetivo exercício na unidade escolar. Ficaram de fora da possibilidade de decisão através da eleição os funcionários da escola que fossem contratados ou comissionados e uma parcela significativa de alunos atendidos pela rede: os alunos dos anos iniciais e finais do ensino fundamental, uma vez que esta faixa de idade desta etapa da educação básica era concentrada entre os 07 e 14 anos de idade. Isso implica na exclusão de grande parte dos destinatários da política da escola na decisão da função diretiva.

Desde a regulamentação inicial da eleição de diretores, a lei foi alterada por decretos do poder executivo que a modificaram em diversos aspectos - limite ao número de reeleições (QUEIMADOS, 2001; 2015a); quanto ao candidato, entrega de documentações que comprovem o desempenho do exercício da função de origem, tempo de serviço no magistério público municipal, tempo de regência de turma, formação em graduação ou pós-graduação em gestão escolar (QUEIMADOS, 1999; 2011), entre outros pontos, conforme apresentado no quadro 1. Após aprovação do PME (QUEIMADOS, 2015), uma nova lei reuniu diversos 
pontos dos textos que alteravam a lei $\mathrm{n}^{\circ} 187 / 95$ (QUEIMADOS, 1995) em um único texto, a lei $n^{\circ}$ 1.278/15 (QUEIMADOS, 2015a) que revogou a lei que inaugurou a forma de selecionar diretores das escolas municipais queimadenses. Desvela-se, assim, que desde a sua aprovação, a lei $n^{\circ}$ 187/95 (QUEIMADOS, 1995) sofreu cinco modificações: quatro das quais por meio de decreto e uma através de lei. Tal movimento nos indica que pode ter havido disputas entre o poder executivo e legislativo, de forma que a referida lei foi alterada, em maior volume, por meio de decretos.

Como destacado por Amaral (2018), compreendemos que lei é o conjunto de normas dispondo sobre determinada matéria e legislação é o conjunto de leis que vigoram no ordenamento jurídico, logo, é formada pela reunião dos códigos, das leis especiais, das normas, portarias, resoluções etc., ou seja, toda a normativa em vigor. Nesse sentido, consideramos a existência de uma espécie de escala que mede a democracia conforme a gestão democrática é disciplinada ou regulamentada em um determinado ente federado. Dependendo das mudanças na regulamentação do processo de eleição de diretores ocorridas por decreto do prefeito ou através de lei, a participação da comunidade escolar e local e dos destinatários da política será diferente. No quadro 1 reunimos os principais pontos das legislações que discorreram sobre a seleção de diretores em Queimados no período de vinte e cinco anos. Neste conjunto, inclui-se o PME (QUEIMADOS, 2015) que versou sobre o tema.

Quadro 1 - Regulamentação da eleição de diretores das escolas municipais em Queimados (RJ)

\begin{tabular}{|c|c|c|c|c|}
\hline $\begin{array}{lr}\text { Legislação } & \text { que } \\
\text { regulamenta } & \text { a } \\
\text { eleição } & \text { de } \\
\text { diretores } & \\
\end{array}$ & $\begin{array}{l}\text { Disposições em relação ao } \\
\text { candidato }\end{array}$ & $\begin{array}{l}\text { Disposições em relação } \\
\text { ao eleitor }\end{array}$ & $\begin{array}{l}\text { Disposições em relação à } \\
\text { comissão eleitoral, à } \\
\text { votação e outros aspectos. }\end{array}$ & Outros aspectos \\
\hline $\begin{array}{l}\text { Lei } n^{\circ} \quad 187 / 95 \\
\text { (QUEIMADOS, } \\
\text { 1995) }\end{array}$ & $\begin{array}{l}\text { Membro do Magistério } \\
\text { Público Municipal com } 5 \\
\text { anos de experiência no } \\
\text { ensino público. }\end{array}$ & $\begin{array}{l}\text { Servidores públicos em } \\
\text { efetivo exercício; } \\
\text { Alunos (+ de } 16 \text { anos) } \\
\text { Pais ou Responsáveis }\end{array}$ & $\begin{array}{l}\text { Comissão eleitoral com } \\
\text { membros indicados } \\
\text { direção da escola. }\end{array}$ & Mandato: 2 anos \\
\hline $\begin{array}{l}\text { Decreto } n^{\circ} 039 / 97 . \\
\text { (QUEIMADOS, } \\
\text { 1997) }\end{array}$ & $\begin{array}{l}\text { Acrescenta regência de turma } \\
\text { na rede pública; } 2 \text { anos em } \\
\text { exercício na escola a que } \\
\text { concorre; } 2 \text { anos experiência } \\
\text { em administração ou função } \\
\text { técnica para candidatos não } \\
\text { especialistas em educação; } \\
\text { programa de trabalho. } \\
\text { Candidatos que não tenham } \\
\text { sofrido penalidade } \\
\text { administrativa. }\end{array}$ & ---------- & $\begin{array}{l}\text { Comissão eleitoral eleita } \\
\text { pelo Conselho Escolar. }\end{array}$ & ---- \\
\hline $\begin{array}{l}\text { Decreto n²03/99 } \\
\text { (QUEIMADOS, } \\
\text { 1999). }\end{array}$ & $\begin{array}{l}\text { Candidato deve } \quad \text { ser } \\
\text { especialista em educação. }\end{array}$ & & ----- & --------- \\
\hline $\begin{array}{l}\text { Lei }^{\circ} 531 / 01 \\
\text { (QUEIMADOS, } \\
\text { 2001) }\end{array}$ & - & ------------ & ----- & $\begin{array}{llr}\text { Mandato: } & 2 & \text { anos, } \\
\text { máximo } & \text { de } & 4 \\
\text { reconduções } & & \\
\end{array}$ \\
\hline $\begin{array}{l}\text { Decreto } n^{\circ} 320 / 01 \\
\text { (QUEIMADOS, } \\
\text { 2001a) }\end{array}$ & & -- & ---- & $\begin{array}{l}\text { Calendário de eleição } \\
\text { definido por portaria. }\end{array}$ \\
\hline
\end{tabular}

RPGE- Revista on line de Política e Gestão Educacional, Araraquara, v. 25, n. 1, p. 168-187, jan./abr. $2021 . \quad$ e-ISSN:1519-9029 


\begin{tabular}{|c|c|c|c|c|}
\hline $\begin{array}{l}\text { Decreto } \mathrm{n}^{\circ} 1272 / 11 \\
\text { (QUEIMADOS, } \\
\text { 2011) }\end{array}$ & $\begin{array}{l}\text { A candidatura fica } \\
\text { condicionada à entrega de } \\
\text { documentação relacionada ao } \\
\text { cargo de origem do do } \\
\text { candidato. }\end{array}$ & ----------" & $\begin{array}{l}\text { Comissão eleitoral eleita e } \\
\text { acompanhada pelo } \\
\text { Conselho Escolar. } \\
\text { A partir da entrega de } \\
\text { documentação } \\
\text { candidatura, a Secretaria } \\
\text { Municipal de Educação } \\
\text { emite Declaração de } \\
\text { Conferência e Parecer } \\
\text { Parcial de cumprimento do } \\
\text { Contrato de Gestão (no } \\
\text { caso de o diretor ou diretor } \\
\text { adjunto em exercício) }\end{array}$ & ------ \\
\hline $\begin{array}{l}\text { Plano Municipal de } \\
\text { Educação - PME } \\
\text { (QUEIMADOS, } \\
\text { 2015) }\end{array}$ & $\begin{array}{l}\text { Meta } 19 \text { - Manter e garantir a } \\
\text { eleição direta, com consulta à } \\
\text { comunidade escolar, para a } \\
\text { função de Diretores das } \\
\text { escolas da rede municipal de } \\
\text { ensino. }\end{array}$ & ------------ & ------------ & --- \\
\hline $\begin{array}{l}\text { Lei n }^{\circ} 1.278 / 15 \\
\text { (QUEIMADOS, } \\
\text { 2015a) }\end{array}$ & $\begin{array}{l}\text { A candidatura fica } \\
\text { condicionada à entrega de } \\
\text { documentação relacionada ao } \\
\text { cargo de origem do } \\
\text { candidato; do magistério } \\
\text { Membro do } \\
\text { público municipal por no } \\
\text { mínimo } 3 \text { anos em exercício } \\
\text { na escola a que concorre. } \\
\text { Formação em Administração, } \\
\text { Gestão Inspeção e } \\
\text { supervisão escolar, } \\
\text { orientação pedagógica ou } \\
\text { orientação educacional; } \\
\text { Disponibilidade de } 40 \text { horas } \\
\text { semanais. }\end{array}$ & $\begin{array}{l}\text { Servidores e demais } \\
\text { funcionários da unidade } \\
\text { escolar. } \\
\text { Aluno maior de } 16 \text { anos } \\
\text { e responsável de aluno } \\
\text { menor de } 16 \text { anos. }\end{array}$ & $\begin{array}{l}\text { Comissão } \\
\text { escolhida em assembleia } \\
\text { geral convocada pelo } \\
\text { diretor em exercício e } \\
\text { acompanhada pelo } \\
\text { Conselho Escolar. } \\
\text { A Secretaria Municipal de } \\
\text { Educação (SEMED) } \\
\text { expede declaração de } \\
\text { adimplência financeira e } \\
\text { parecer para os diretores } \\
\text { em exercício. }\end{array}$ & 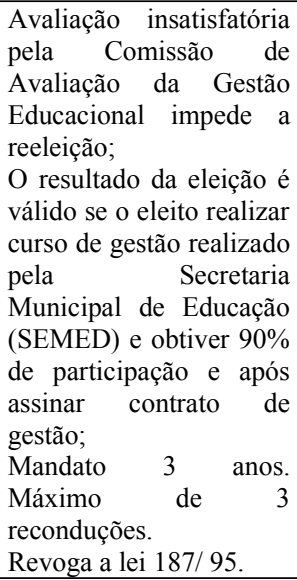 \\
\hline
\end{tabular}

Fonte: Elaborado pelas autoras

A política, como texto, é fruto de múltiplas agendas e influências, mudam de acordo com as arenas e interpretações, com os textos e contextos que carregam consigo as suas histórias (BALL, 1994). O momento em que a política de eleição de diretores foi gestada, poucos anos após a emancipação do munícipio, representou demandas daquele período e foram (re)contextualizadas ao passo em que avançava nessa política. Observa-se que o desempenho do candidato não tomava relevo na lei $n^{\circ} 187 / 95$ (QUEIMADOS, 1995). No entanto, a trajetória da regulamentação da eleição de diretores aponta que o desempenho do candidato passa a ser um quesito relevante, caminhando para um modelo mais meritocrático e de performatividade. É observável um movimento de aferição nesse sentido: os candidatos à eleição devem entregar à SEMED documentação comprobatória de suas funções de forma que, através de Declaração de Conferência da referida documentação e Parecer a serem emitidos pela pasta, serão considerados aptos para a candidatura junto à Comissão Eleitoral. O Parecer é emitido pela Comissão de Avaliação da Gestão Educacional (CADEGE) com membros indicados pela secretaria de educação, mas não há previsibilidade na lei $n^{\circ} 1.278 / 15$ (QUEIMADOS, 2015a) de quantas pessoas e quais a comporão: se técnicos da própria 
secretaria, sujeitos da escola, pais e responsáveis e alunos, nem mesmo quais critérios são levados em conta para a emissão do parecer.

Antes mesmo da candidatura, o poder executivo realiza com esse processo uma espécie de pré-seleção através da averiguação da documentação a ser reunida e entregue pelo candidato o que aponta uma tutela do processo, perpassada pelo crivo da secretaria. A esse respeito, Ball (2005, p. 543) considera que:

Os desempenhos de sujeitos individuais ou de organizações servem de parâmetros de produtividade ou de resultado, ou servem ainda como demonstrações de "qualidade" ou "momentos" de promoção ou inspeção. Eles significam ou representam merecimento, qualidade ou valor de um indivíduo ou organização dentro de uma área de julgamento, tornando os "silêncios audíveis".

A essa condição o autor concebe o conceito de performatividade: os sujeitos são aferidos pela comprovação transcrita de suas práticas, cabendo a eles - ou não - pleitear o espaço da direção escolar. A eleição é uma forma de democratização da escola antes mesmo do dia da decisão em si. Antes disso, deve-se considerar se o acesso dos candidatos a este processo também é democrático. A aferição de performatividade que limita a participação dos candidatos no processo eleitoral vai de encontro a própria ideia da eleição. Se por um lado quem está na escola deve decidir através do voto o seu representante na direção escolar, quem está na escola, igualmente deve ter acesso à candidatura - desde que cumpridas as exigências estabelecidas na LDB (BRASIL, 1996). Cada rede de educação irá definir o perfil do diretor dentro da sua autonomia, contudo, perfis muito específicos limitam a participação dos sujeitos no jogo democrático.

Ao longo das mudanças trazidas no bojo da lei de eleições para os diretores das escolas públicas em Queimados, seja por decreto, seja por lei, a definição dos eleitores não foi ampliada: nos vinte e cinco anos de existência da legislação de eleição de diretor escolar em Queimados a participação do destinatário da política no processo de eleição não foi considerada. A assertiva se sustenta pela manutenção do voto por aluno matriculado na rede municipal a partir dos 16 anos de idade, o que pode corresponder a uma leitura por parte do poder legislativo local da legislação eleitoral brasileira num viés mais legalista e menos inclusivo uma vez que, no Brasil, o voto é facultado a partir dos 16 anos de idade. 
Os dados dos questionários da Prova Brasil 20174, aplicados aos alunos do $5^{\circ}$ ano do ensino fundamental apontaram a existência de uma parcela ínfima de alunos com mais de 15 anos era atendida pela rede nesse ano de escolaridade. Somente 17 alunos tinham idade maior que 15 anos, o que significa $1 \%$ dos estudantes matriculados nesta série. Isso significa que poucos alunos no $5^{\circ}$ ano poderiam votar e participar naquele ano da decisão sobre quem assumirá a função de diretor de escola. A tendência é que nas séries antecedentes ao $5^{\circ}$ ano do ensino fundamental a idade dos alunos seja inferior, que, se confirmada, representa uma parcela ainda menor nas demais séries do primeiro segmento do ensino fundamental. As maiores faixas de idade entre alunos matriculados no $5^{\circ}$ ano na rede municipal, de acordo com as respostas dos questionários, são de 10 e 11 anos - 26\% e 48\%, respectivamente.

Quando analisados os questionários aplicados aos alunos do $9^{\circ}$ ano de escolaridade, observa-se há maior possibilidade de participação dado que todos os estudantes respondentes eram nascidos em 2000 ou antes, isto é, todos poderiam ser eleitores caso houvesse eleição para diretor de escola naquele ano. Os dados apontam que a participação pode ser levemente ampliada no segundo segmento do ensino fundamental devido a provável distorção idadesérie, considerando que a idade compreendida no ensino fundamental - oferecido pela rede municipal de Queimados é dos 6 aos 14 anos.

A contração da participação de diferentes eleitores é uma das formas vistas por Lima (2014) de como reduzir o potencial democrático da eleição. Se por um lado o município abre a participação dos sujeitos da escola para a decisão através do voto, por outro, a democracia é desidratada (AMARAL, 2019) ao limitar a participação dos estudantes, destinatários da política e para quem a escola existe. Nesta análise cabe pontuar que o conselho escolar, que anteriormente definia a formação da Comissão Eleitoral nas escolas, passa a acompanhar a formação, mas não fica claro se o colegiado decide os membros da comissão. A quantidade de reconduções de um diretor eleito indica sobre a possibilidade de manutenção de uma mesma pessoa na função, o que pode cortiná-la de personalismo. No caso queimadense, ampliou-se o tempo de mandato de dois para três anos. Em contrapartida, o limite de reconduções passa de

4 A Prova Brasil e o Sistema Nacional de Avaliação da Educação Básica (Saeb) são avaliações para diagnóstico, em larga escala, desenvolvidas pelo Instituto Nacional de Estudos e Pesquisas Educacionais Anísio Teixeira (Inep/MEC). Tem o objetivo de avaliar a qualidade do ensino oferecido pelo sistema educacional brasileiro a partir de testes padronizados e questionários socioeconômicos. Professores e diretores das turmas e escolas avaliadas também respondem a questionários que coletam dados demográficos, perfil profissional e de condições de trabalho. Utilizamos os dados dos questionários da Prova Brasil 2017 aplicados a alunos do $5^{\circ}$ e $9^{\circ}$ ano do ensino fundamental. No que se refere ao $5^{\circ}$ ano de escolaridade, foram aplicados 1849 questionários e foram considerados com respostas válidas 1420 questionários. No $9^{\circ}$ ano de escolaridade foram aplicados 500 questionários, sendo 401 considerados com respostas válidas. Estes dados podem ser consultados em: https://www.qedu.org.br/cidade/2794-queimados/pessoas/aluno5ano; https://www.qedu.org.br/cidade/2794queimados/pessoas/aluno9ano. Acesso em: set. 2019. 
quatro para três vezes. O tempo máximo de permanência do diretor na função passa de oito para nove anos. Isto implica em uma ampliação do tempo em que um mesmo sujeito esteja na função de diretor escolar, o que pode não favorecer aspectos democráticos, dado que limita a possibilidade de oxigenação da gestão da escola. Se por um lado a eleição de diretores em Queimados se parece com o processo eleitoral para a escolha de presidente, governador e prefeito, por outro lado se afasta quando o limite de permanência destes chefes do poder executivos no cargo é de no máximo oito anos, ou dois mandatos sequenciais.

A eleição para a escolha de diretores das escolas públicas não é desprovida de limitações, entretanto é a opção mais indicada por ser democraticamente superior as demais formas e considerada por Lima (2014, p. 1071) a "mais favorável à possível combinação entre práticas de democracia direta e práticas de democracia representativa nas escolas". Em um contexto marcado por práticas patrimonialistas e clientelistas como o da Baixada Fluminense, lócus que, para Hora (2010), apresenta em si uma importante identidade social, cultural, geográfica, econômica devido a sua origem histórica, a abertura da participação da comunidade escolar por meio da eleição de diretores, afastando-se da indicação política, ainda que com limitações, representa um passo para frente em relação às práticas historicamente estabelecidas.

Ainda no debate sobre a seleção de diretores através da eleição cabe aqui a discussão sobre uma forma de selecionar profissionais para essa função: a consulta pública. Inaugurada nos textos oficiais pelo PNE (BRASIL, 2014), a consulta pública, como forma de escolha de diretores, é um processo dissemelhante da eleição. A principal característica que distingue as duas formas concentra-se no próprio formato e nos instrumentos que cada um desses modelos utiliza para perceber o desejo daqueles que estão na escola. Enquanto a eleição conta com o voto dos integrantes da comunidade escolar - salvo as possíveis limitações de participação para escolher o mais votado para a função de diretor ou diretora de escola, a consulta pública não se utiliza necessariamente do voto para a escolha.

A eleição por voto secreto e pessoal garante aos eleitores a privacidade da escolha. A consulta, se por aclamação, pode induzir os participantes a um voto que não necessariamente representa a sua decisão, dado que dessa forma, por não haver privacidade da opção do consultado. Ademais, a consulta pública pode não seguir a candidatura de chapas, como na eleição, o que pode cercear, dessa vez, a participação dos que pretendem pleitear a função de diretor escolar. Outra variação da consulta que reduz as possibilidades de participação é o modelo de consulta por lista. No caso de o poder executivo indicar nomes internos ou externos da escola para serem submetidos à consulta dos membros da comunidade escolar, 
nem todos que porventura desejassem participar da consulta poderiam ser indicados, o que poderia depender da relação desse indivíduo com o poder executivo.

Ainda na consulta pública, o poder executivo pode não necessariamente nomear o candidato mais votado e qualquer dos integrantes da comunidade escolar que tenha o mérito e o desempenho necessário pode candidatar-se, contudo a secretaria de educação ou o prefeito escolhe, dentre os mais votados, aquele que será nomeado em uma lista tríplice. Por outro lado, a consulta pode ampliar as possibilidades de participação se comparada à eleição de diretores que acompanha os moldes das eleições no Brasil, como é o caso de Queimados, onde a tutela do voto vai até os 16 anos, impedindo a participação dos que estão abaixo desta faixa de idade.

A consulta pública e a eleição são formas distintas que podem ter variações, possibilidades e limitações de participação. Consideramos que a eleição é o mecanismo mais abrangente para selecionar diretores de escolas públicas, ainda que esse formato possa apresentar fragilidades, dependendo de como é regulamentado. A análise de como está posta em cada um dos cenários é que pode afirmar quão participativo ou não pode ser cada um desses tipos de seleção, a partir de como cada um deles está normatizado nas unidades subnacionais brasileiras para os seus sistemas de ensino.

Destacamos, ainda, que em 2009 o Supremo Tribunal Federal (STF) ratificou seu entendimento de que a realização de eleições diretas para provimento de cargos comissionados nas diretorias de escolas públicas é inconstitucional. A decisão foi tomada no julgamento da Ação Direta de Inconstitucionalidade (ADI) 2997 (SUPREMO TRIBUNAL FEDERAL, 2009), ajuizada na Corte pelo Partido Social Cristão (PSC) contra dispositivos da Constituição Estadual do Rio de Janeiro e outras normas derivadas. O dispositivo questionado (artigo 308, inciso XII, da Constituição Estadual Fluminense) define que as eleições para a direção de instituições de ensino públicas estaduais no Rio de Janeiro deveriam ser feitas de forma direta e com a participação da comunidade escolar. Para o Partido Social Cristão (PSC), o cargo de diretor de unidades escolares é um cargo em comissão, cujo provimento "pertence à esfera discricionária do chefe do Poder Executivo, em cuja estrutura organizacional aquele cargo se insere". As normas ferem os princípios constitucionais da independência dos poderes e da gestão democrática do ensino, além de afrontar os artigos 37, XI (exigência de concurso para ingresso nos cargos públicos); 61, II, "c" (competência privativa do Presidente da República para propor leis sobre servidores públicos federais); e 84, II e XXV (competência exclusiva do Presidente da República para exercer a direção da administração federal e prover e extinguir os cargos públicos federais). O relator do processo, 
ministro Cezar Peluso, lembrou que o tema já foi amplamente discutido e pacificado pela Corte. Assim, com base em diversos precedentes, o ministro votou pela procedência da ação, entendimento que foi seguido à unanimidade pelos demais ministros presentes à sessão. Nesse contexto, o PNE 2014-2024 faz uso do termo consulta à comunidade quando trata da seleção de diretores, afastando-se de problemas legais e induzindo os entes federados a mesma estratégia em seus planos de educação. Mais de uma década após este entendimento, questionamos se já não é passado o momento de repensar este debate, considerando o que Amaral (2019) vai chamar de desidratação da democracia. Concordamos que a escola pública, nesse sentido, é lugar de tratar e aprofundar a prática e o exercício contraditório desde as etapas iniciais da educação básica.

O município de Queimados não se adequou ao Plano Nacional de Educação, uma vez que orienta a seleção dos diretores de escolas públicas a partir de critérios técnicos de mérito e desempenho e a consulta pública à comunidade. Ao invés, a meta 19 do PME (QUEIMADOS, 2015) traz a seguinte redação: "Manter e garantir a eleição direta, com consulta à comunidade escolar, para a função de Diretores das escolas da rede municipal de ensino". Ao permanecer no PME a manutenção pela gestão municipal da eleição de diretores, conforme balizado nos seus documentos legais (QUEIMADOS, 1993; 1995) gera um movimento de infidelidade normativa (LIMA, 2011) e, simultaneamente, uma espécie de auto fidelidade, dado que todos os seus textos políticos se ancoram no modelo de eleição de diretores. A eleição de diretores para as escolas municipais pode ser, desta forma, considerada uma marca das políticas para a gestão da educação pública de Queimados desde a sua emancipação, mas com acidentes neste percurso.

\section{Considerações finais}

O presente trabalho objetivou a análise dos textos políticos que regulamentaram a seleção de diretores das escolas públicas do município de Queimados (RJ). O município que, desde o início da década de 1990, já se organizava de forma a atender o princípio de gestão democrática previsto na CF (BRASIL, 1988), antes mesmo da sanção da LDB em 1996 (BRASIL, 1996) que ratificou o princípio. No entanto, a participação, uma das dimensões de gestão democrática, que permeia as dimensões de eleição e colegialidade é fragilizada quando em mais de duas décadas de eleição de diretores, o aluno, destinatário da política, não decide e o seu voto é tutelado. Outra fragilidade do processo de eleição de diretores para as escolas municipais queimadenses se dá pela impossibilidade de outros funcionários que não sejam 
docentes possam candidatar-se ao pleito. O processo de participação na eleição inicia-se antes do momento do voto em si, quando os atores escolares podem optar pela candidatura, desde que possuam a formação necessária.

Após o PNE, o município reformula todos os textos que versavam sobre a eleição de diretores em uma única lei. Frente ao texto do PNE, gerou uma infidelidade normativa ao afastar-se da consulta pública para a escolha de diretores e concomitantemente gera uma auto fidelidade, pois mantém a eleição como desde a Lei Orgânica Municipal. Cada política formulada nesse sentido carece de análise, pois a existência de eleição de diretores não garante a democratização da decisão da escola, como pudemos observar em Queimados, dado que o aluno, destinatário das políticas da escola, não participa do pleito. Observa-se uma tutela também por parte do poder executivo quanto a candidatura dos docentes interessados, sem clareza de quais atores comporão, a cada eleição, a comissão da pasta da educação determinada a conferência dos trâmites burocráticos para ratificar a intenção ao pleito dos candidatos.

Embora o município em tela tenha normatizado por meio da eleição o princípio da gestão democrática posto na CF (BRASIL, 1988), a participação, como dimensão crucial não é o centro do processo, do contrário, a averiguação do mérito e desempenho do candidato e a auto fidelidade são os grandes pontos chave que se destacam na análise.

\section{REFERÊNCIAS}

AMARAL, D. P. Critérios técnicos e participação da comunidade na seleção de diretores de escolas públicas no Rio de Janeiro: qual gestão democrática em cena? In: NAJJAR, J.; BAENSI, A. V.; VICENTE, D. S. Conselhos Escolares e Gestão Democrática: alguns temas em debate. Rio de Janeiro: Ministério Público do Estado do Rio de Janeiro, Universidade Federal Fluminense, Grupo Articulador de Fortalecimento dos Conselhos Escolares do Estado do Rio de Janeiro, 2019.

AMARAL, D. P. Seleção de diretores de escolas públicas e avaliação do desempenho do candidato. Revista Retratos da Escola, Brasília, v. 12, n. 22, p. 43-55, jan./jun. 2018.

BALL, S. Education reform: what is policy. Texts, trajectories and toolboxes. USA: Open University Press, 1994.

BALL, S. Profissionalismo, gerencialismo e perfomatividade. Cadernos de Pesquisa, São Paulo, v. 35, n. 126, p. 539-564, set./dez. 2005. DOI: https://doi.org/10.1590/S010015742005000300002

BOWE, R.; BALL, S.; GOLD, A. Reforming education and changing schools. Cases studies in policy sociology. The police process and the processes of policy. London: Routledge, 1992.

RPGE- Revista on line de Política e Gestão Educacional, Araraquara, v. 25, n. 1, p. 168-187, jan./abr. 2021. 
BRASIL. Constituição da República Federativa do Brasil de 1988. Brasília, DF: Senado Federal, 1988. Disponível em:

http://www.planalto.gov.br/ccivil_03/Constituicao/ConstituicaoCompilado.htm. Acesso em: 15 abr. 2018.

BRASIL. Lei n. 9394, de 20 de dezembro de 1996. Estabelece as diretrizes e bases da educação nacional. Brasília, 23 dez. 1996. Disponível em:

http://www.planalto.gov.br/ccivil_03/leis/L9394.htm. Acesso em: 10 mar. 2018.

BRASIL. Lei n. 13.005, de 25 de junho de 2014. Aprova o Plano Nacional de Educação PNE e dá outras providências. Brasília, 26 jun. 2014. Disponível em:

http://www.planalto.gov.br/CCIVIL_03/_Ato2011-2014/2014/Lei/L13005.htm. Acesso em: 10 maio 2018

FERNÁNDEZ, S. J. Projeto político-pedagógico e cotidiano escolar: retrospectivas, deslocamentos e possibilidades. In: AMARAL, D. P. (Org.). Gestão escolar pública: desafios contemporâneos. Rio de Janeiro: UNESCO, 2015. p. 41-60.

HORA, D. L. Gestão dos sistemas educacionais: modelos e práticas exercidas na Baixada Fluminense. RBPAE, v. 26, p. 565-581, 2010.

LIMA, L. Por que é tão difícil democratizar a gestão da escola pública? Educar em Revista, Curitiba, v. 34, n. 68, p. 15-68, mar./abr. 2018.

LIMA, L. A gestão democrática das escolas: do autogoverno à ascensão de uma pósdemocracia gestionária? Educação e Sociedade, Campinas, v. 15, n. 129, p. 1067-1083, out./dez. 2014. DOI: https://doi.org/10.1590/ES0101-73302014142170

LIMA, L. Administração escolar: estudos. Porto: Porto Editora, 2011, p. 168-171.

MENDONÇA, E. F. Estado Patrimonial e gestão democrática do ensino público no Brasil. Educação e Sociedade, Campinas, n. 75, p. 84-108, ago. 2001. DOI:

https://doi.org/10.1590/S0101-73302001000200007

PARO, V. H. Crítica da estrutura da escola. São Paulo: Cortez, 2011.

PARO, V. H. Gestão democrática da escola pública. 4. ed. São Paulo: Cortez, 2016, p. 21 36.

PARO, V. H. O princípio da gestão democrática no contexto da LDB. In: OLIVEIRA, R. P.; ADRIÃO, T. (Org.). Gestão, financiamento e direito à educação: análise da Constituição Federal e da LDB. São Paulo: Xamã, 2007. p. 73-81.

QUEIMADOS. Câmara Municipal de Queimados. Lei Orgânica Municipal de 1993. 1993. Disponível em: http://www.queimados.rj.gov.br/leis.asp. Acesso em: 15 mar. 2018. QUEIMADOS. Lei n. 187, de 25 de agosto de 1995. Regulamenta o processo de eleições de diretores das Unidades da Rede Pública Municipal e dá outras providências. 1995. Disponível em: http://www.queimados.rj.gov.br/leis.asp. Acesso em: 10 jun. 2018. 
QUEIMADOS. Decreto n. 39, de 28 de agosto de 1997. Normatiza o processo de Eleição de Diretores das Unidades Escolares do Sistema Público Municipal e dá outras providências. 1997. Disponível em: https://queimados.rj.gov.br/arquivos_lei/DEC_039.PDF. Acesso em: 10 jun. 2018

QUEIMADOS. Decreto n. 203, de 23 de novembro de 1999. Normatiza o processo de eleição de diretores das unidades escolares do sistema público municipal. 1999. Disponível em: http://www.queimados.rj.gov.br/leis.asp. Acesso em: 10 mar. 2018.

QUEIMADOS. Lei n. 531, de 14 de agosto de 2001. Altera a redação do art. $2^{\circ}$ da lei $\mathrm{n}^{\circ} 187 / 95$, de 25 de agosto de 1995. 2001. Disponível em:

http://www.queimados.rj.gov.br/leis.asp. Acesso em: 10 mar. 2018.

QUEIMADOS. Decreto n. 320, de 28 de setembro de 2001. Altera o Decreto no 203/99 que normatiza o processo de eleição dos Diretores das Unidades Escolares do Sistema Público Municipal e dá outras providências. 2001a. Disponível em:

https://queimados.rj.gov.br/arquivos_lei/DEC_320.PDF. Acesso em: 01 de outubro de 2020.

QUEIMADOS. Decreto n. 1.272, de 07 de outubro de 2011. Altera o artigo $2^{\circ}$ do Decreto 203/99, que normatiza o processo de eleição dos diretores escolares do sistema público municipal e dá outras providências. 2011. Disponível em:

http://www.queimados.rj.gov.br/leis.asp. Acesso em: 20 maio 2020.

QUEIMADOS. Lei n. 1251, de 15 de julho de 2015. Aprova o Plano Municipal de Educação - PME e dá outras providências. 2015. Disponível em:

http://www.queimados.rj.gov.br/leis.asp. Acesso em: 15 jul. 2018.

QUEIMADOS. Lei n. 1278, de 10 de novembro de 2015. Dispõe sobre o processo de eleições de diretores das unidades públicas da rede municipal e dá outras providências. 2015a. Disponível em: http://www.queimados.rj.gov.br/leis.asp. Acesso em: 20 maio 2018.

ROCHA, J. M.; LÚCIO JORGE, H. Gestão e democracia em uma escola pública. RBPAE, v. 34, n. 2, p. 635-652, maio/ago. 2018.

SANTOS, M. C. G.; SALES, M. P. S. Gestão democrática da escola e gestão do ensino: a contribuição docente à construção da autonomia na escola. Revista Ensaio, Belo Horizonte, v. 14, n. 2, p. 171-183, ago./ nov. 2012. DOI: https://doi.org/10.1590/1983-21172012140211

SOUZA, Â. R. Explorando e construindo um conceito de gestão escolar democrática.

Educação em Revista, Belo Horizonte, v. 25, n. 03, p. 123-140, dez. 2009. DOI:

https://doi.org/10.1590/S0102-46982009000300007

SUPREMO TRIBUNAL FEDERAL. STF. Ação Direta de Inconstitucionalidade n 2997.

É inconstitucional toda norma que preveja eleições diretas para direção de instituições de ensino mantidas pelo Poder Público, com a participação da comunidade escolar. Disponível em: http://www.stf.jus.br/portal/cms/verNoticiaDetalhe.asp?idConteudo=\%20111821. Acesso em: 10 nov. 2018 


\section{Como referenciar este artigo}

BITTENCOURT, B.; AMARAL, D. P. A gestão democrática no contexto do município de Queimados (RJ): a trajetória de eleição para diretores escolares. Revista on line de Política e Gestão Educacional, Araraquara, v. 25, n. 1, p. 168-187, jan./abr. 2021. e-ISSN:1519-9029. DOI: https://doi.org/10.22633/rpge.v25i1.13896

Submetido em: $16 / 04 / 2020$

Revisões requeridas em: 10/07/2020

Aceito em: 01/10/2020

Publicado em: 02/01/2021 